\title{
LagC is required for cell-cell interactions that are essential for cell-type differentiation in Dictyostelium
}

\author{
Joseph L. Dynes, Alexandra M. Clark, Gad Shaulsky, Adam Kuspa, William F. Loomis, \\ and Richard A. Firtel ${ }^{1}$ \\ Department of Biology, Center for Molecular Genetics, University of California, San Diego, La Jolla, California \\ 92093-0634 USA
}

\begin{abstract}
Strain AK127 is a developmental mutant of Dictyostelium discoideum that was isolated by restriction enzyme-mediated integration (REMI). Mutant cells aggregate normally but are unable to proceed past the loose aggregate stage. The cloned gene, lagC (loose aggregate $\mathrm{C}$ ), encodes a novel protein of $98 \mathrm{kD}$ that contains an amino-terminal signal sequence and a putative carboxy-terminal transmembrane domain. The mutant strain AK127 shows no detectable lagC transcript upon Northern analysis, indicating that the observed phenotype is that of a null allele. Expression of the lagC cDNA in AK127 cells complements the arrest at the loose aggregate stage, indicating that the mutant phenotype results from disruption of the lagC gene. In wild-type cells, lagC mRNA is induced at the loose aggregate stage and is expressed through the remainder of development. $\operatorname{lagC} C^{-}$null cells aggregate but then disaggregate and reaggregate to form small granular mounds. Mature spores are produced at an extremely low efficiency $(<0.1 \%$ of wild type), appearing only after $\sim 72 \mathrm{hr}$, whereas wild-type strains produce mature spores by $26 \mathrm{hr}$. lagC $\mathrm{C}^{-}$null cells accumulate reduced levels of transcripts for the prestalk-enriched genes rasD and $C P 2$ and do not express the DIF-induced prestalk-specific gene $e c m A$ or the cAMP-induced prespore-specific gene $S P 60$ to significant levels. In chimeric organisms resulting from the coaggregation of $\mathrm{lagC}^{-}$null and wild-type cells, cell-type-specific gene expression is rescued in the $\operatorname{lag} C^{-}$null cells; however, $\operatorname{lagC} C^{-}$prespore cells are localized to the posterior of the prespore region and do not form mature spores, suggesting that $\mathrm{LagC}$ protein has both no cell-autonomous and cell-autonomous functions. Overexpression of $\operatorname{lag} C$ from an actin promoter in both wild-type and lagC ${ }^{-}$cells causes a delay at the tight aggregate stage, the first stage requiring LagC activity. These results suggest that the LagC protein functions as a nondiffusible cell-cell signaling molecule that is required for multicellular development.
\end{abstract}

[Key Words: Dictyostelium discoideum; cell-cell interactions; signal transduction, developmental mutation]

Received December 10, 1993; accepted in revised form March 2, 1994.

Removal of nutrients from Dictyostelium discoideum initiates a developmental process that culminates with the formation of a fruiting body consisting of spores held up by stalk cells. The first step in the formation of this multicellular structure is the aggregation of individual amoebae through chemotaxis to extracellular cAMP (Konijn et al. 1968). Within the aggregate, cells fated to become stalk or spores can be distinguished by the expression of cell-type-specific genes (Mehdy et al. 1983; Krefft et al. 1984; Morrissey et al. 1984; Gomer et al. 1986; Williams et al. 1989; Esch and Firtel 1991; Haberstroh and Firtel 1990; Fosnaugh and Loomis 1993). These initially intermixed prestalk and prespore cells then sort out to establish spatial patterns that persist throughout culmination. In response to extracellular cAMP, prestalk

'Corresponding author. cells migrate through the aggregate to form the tip, which acts as an "organizer" during the rest of Dictyostelium development (Raper 1940; Traynor 92). The tip of the aggregate elongates to form the first finger, which then falls onto the substratum to produce the migrating slug that eventually culminates, forming a mature fruiting body. The entire developmental process takes $\sim 24 \mathrm{hr}$ (Loomis 1982).

Extracellular cAMP plays a key role during subsequent development as a regulator of prestalk- and prespore-specific genes. Induction of these genes requires high levels of cAMP produced within the aggregate, which then binds to cell-surface receptors and activates $G$ proteincoupled signaling pathways (for reviews, see Firtel 1991; Kimmel and Firtel 1991; Schaap 1991; Williams 1991). Prestalk-specific and prestalk-enriched genes, which are induced early in this process [e.g. rasD and pst-cathep$\sin / C P 2(\operatorname{cpr} B)]$, can be induced to a low level in starving 
cells in shaking culture by the addition of nanomolar pulses of cAMP that mimic signaling during aggregation (Mehdy et al. 83; Reymond et al. 1984; Mehdy and Firtel 1985; Pears et al. 1985; Datta et al. 1986; Jermyn et al. 1987). These genes are then fully induced in response to high levels of cAMP. Prespore genes such as $S P 60(\cot C)$, $S P 70(\cot B)$, and $p s p B$ require cell-cell contact, in addition to high levels of cAMP, for expression (Mehdy et al. 83; Chisholm et al. 84; Mehdy and Firtel 1985; Fosnaugh and Loomis 1991; Powell-Coffman and Firtel 1994). The prestalk gene $e \mathrm{~cm} A$ requires DIF (differentiation inducing factor) in addition to cAMP for maximal expression (Williams et al. 1987; Berks and Kay 1990). lacZ reporter constructs driven by these cell-type-specific promoters have been used to study spatial patterning and temporal differentiation of cell types in wild-type and mutant strains, and to follow cellular differentiation in chimeras containing wild-type and mutant cells (Haberstroh and Firtel 1990; Esch and Firtel 1991; Mann and Firtel 1991, 1993; Hadwiger and Firtel 1992; Hooper 93; Fosnaugh and Loomis 1993).

Recently, a technique for insertional mutagenesis in Dictyostelium, termed restriction enzyme-mediated integration (REMI) was developed (Kuspa and Loomis 1992). The technique involves introduction of an active restriction enzyme along with linearized vector DNA containing compatible cohesive ends into Dictyostelium cells. High-efficiency integration occurs at chromosomal sites recognized by the restriction enzyme. REMI is mutagenic in Dictyostelium, and developmental mutants have been isolated at a frequency of $0.3-1 \%$ of the transformants. The vector-tagged mutated genes in these strains can then be isolated by excising the vector and flanking DNA with a second restriction enzyme, followed by circularizing the DNA with ligase and transforming into Escherichia coli.

Strain AK127 was identified in the initial REMI screen for developmental mutants and shown to contain a single vector insert (Kuspa and Loomis 1992). Morphogenesis in this strain is blocked at the loose aggregate stage. Because of the observed phenotype, the affected gene was designated lagC (loose aggregate mutant $\underline{\mathrm{C}}$ ). The mutant phenotype was regenerated by transforming linearized vector DNA carrying flanking sequences into wild-type Dictyostelium cells. Homologous recombination into the lagC gene indicated that phenotype results from disruption of this gene (Kuspa and Loomis 1992; Dynes et al. this paper). This paper reports the analysis of strain AK127, and the cloning and molecular characterization of $\operatorname{lag} C$. We show that $\operatorname{lag} C$ encodes a developmentally regulated, putative transmembrane domain protein that is essential for the expression of genes induced after aggregate formation in vivo and in shaking culture in response to high levels of cAMP. Analysis of chimeric organisms marked with cell-type-specific reporter genes shows that $\mathrm{LagC}$ has both cell-autonomous and non-cellautonomous functions and indicates that $\operatorname{lag} C$ is involved in cell-cell interactions that are essential for cellular morphogenesis. Our results suggest that the $\operatorname{lag} C$ mutation identifies a previously unknown component of a signaling pathway that is essential for multicellular differentiation in Dictyostelium.

\section{Results}

\section{lagC $c D N A$ and protein sequence}

Plasmid p127Cla contains Dictyostelium genomic sequences from around the vector insertion site (IS127) in strain AK127 (Kuspa and Loomis 1992). These sequences were used to isolate a 3.0-kb lagC cDNA, termed c127.1, from a library that was constructed using RNA isolated at 12-16 hr of development (Fig. 1; Schnitzler et al. 1994; see Materials and methods). In the cDNA clone, the DNA sequence around the unique $B a m H I$ site matched the sequence obtained from the genomic fragment adjacent to the BamHI site at the insertion point (Fig. 1). Analysis of the DNA sequence identified a single long open reading frame that encodes an 888 -amino-acid protein with a molecular mass of $98 \mathrm{kD}$, beginning with the first methionine codon in the cDNA (Fig. 2, top). The cDNA contains $\sim 200$ bp of 5 '-untranslated sequence and $\sim 30$ bp of 3 '-untranslated sequence. The base composition of the untranslated sequences is typical for Dictyostelium noncoding regions $(\sim 90 \% \mathrm{~A}+\mathrm{T}$ ) (Kimmel and Firtel 1983). Hydrophobicity analysis of the protein sequence and comparison to published data bases predicted three structural features. There is a 17-amino-acid amino-terminal signal sequence and a 24-amino-acid carboxy-terminal glycine-rich hydrophobic putative transmembrane domain with a 14-amino-acid hydrophilic basic carboxy-terminal tail. The putative processed protein would be 871 amino acids, with a molecular mass of $96 \mathrm{kD}$, as predicted by the signal sequence cleavage algorithm of von Heijne (1986). We expect that the long amino-terminal region containing 17 cysteines would not be cytoplasmic (see Discussion).

Both the nucleotide and amino acid sequences of LagC were compared with other available sequences using the BLAST and BLOCKS programs (Altschul 1990; Henikoff and Henikoff 1991). The putative transmembrane domain was found to be similar to the putative transmembrane domain of the protein cell-CAM105 (C-CAM),

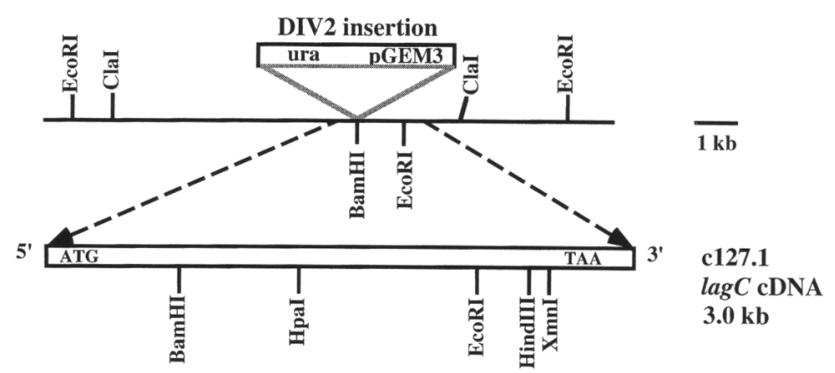

Figure 1. $\operatorname{lag} C$ genomic and cDNA map. The position of insertion of the REMI vector DIV2 into the BamHI site of the lagC gene as well as other restriction sites and start and stop codons is shown. DIV2 inserted $\sim 560$ bp from the start codon of $\operatorname{lagC}$ in the strain AK127, causing a $\log C^{-}$null mutation. 


\begin{abstract}
MEKKIILLIL FLFFISGYSM NPPTPIDAIY DDKLFTLIFN SNLPYSTRLI LYKNEKEPRT EMAPNYFNCS LVDGERHCLF HSDEPFSRLW GSIDSKVCVR DKSNTVEDCT FDASGLVYYP KVYNLKYSKK PKTSGEDIVI TGSYLRLFGG PNFLINSIDV NKPFVVKGNF SDPSFDCNNI TVTFPPGSGK FRLYYDETGD NPVPFSYESP IISSSVSDSS KQIITINGDN FFTDKDLVKV SFDGIDQPNF IISVNHKQIQ VNNYNRVDPG PMSVNITVDE VSIEKNYIHC FPAIITSISS VSNHLDGIVT IKGEKLSSTL NYYLTPSITI GDKYVIIKST TTELECKLDA NELGGKNLPV NVNFGGCDST SPNGVSFTYN IPTLSRGSYS NGIVTLIGTN LGTNNESSIQ LYGDGIKNTN ISQFNVSSSD EKSVTFELPH LRCRSFNINF TRSGITAKTL SISASLSVNV INRPTVSNGI LNIEIYYMDC TISSSAPSIT VGDSSSASPC SIPSSNSSYY ETTCPTPYGT GINKQFIFKL NSETVSDQFS YAPPEVENRT ISDDGTNIEL HGNNFGNSTS LIKVYLNGSD ISSEIQELED HQLTIKILDS YENGPINITV DGNYMDSLFY LTLPPVIYRI TNKDNKTLAC GGLITVSGKN LLTSDKEFKV NVKSNNKNTT VFAQDEKILI VRDESRESSL FVTTFIGVRS GPSTTLTYIK PMISEIPTIE NKIEKGILAI IRGYSFTDIL NASLTVSSET VPLSCNLECS LSPNEILDDS DSSETNITNS NTDCLSCHSG SSVKNTSGVL YLLFNSTSFQ YNVTIEEIKL SPSPNVSQRD VETKSSKPSN GLIIGSTIGS VGGALAIGAL AYYFKIPFRV KKFIGKKF
\end{abstract}

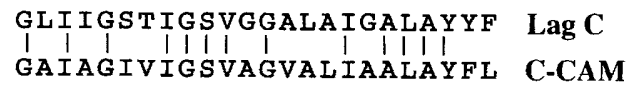

Figure 2. Derived amino acid sequence of LagC protein and sequence comparison in the putative transmembrane domain with C-CAM. (Top) The signal sequence and putative transmembrane domain are indicated by shading; (bottom) sequence comparison of the putative transmembrane domains of LagC and C-CAM. Identities are marked by a vertical line. (Note the conservative changes of some of the nonidentical amino acids.)

which is a mammalian cell adhesion molecule and extracellular ATPase (Aurivillius et al. 1990; Öbrink 1991). The identity in this 24 -amino-acid region is $54 \%$ (Fig. 2B). The transmembrane domain of the human herpes virus glycoprotein $\mathrm{D}$ and the predicted transmembrane domains of the sea urchin egg peptide (speract) receptor and several members of the murine carcinoembryonic antigen family share a similar glycine-rich transmembrane structure (McGeoch et al. 1985; Hinoda et al. 1988; Dangott et al. 1989; Dveksler et al. 1991). No other significant sequence homologies were found.

\section{Regulation of lagC $m R N A$ expression}

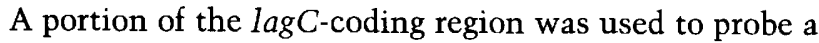
developmental RNA blot to examine lagC expression kinetics (Fig. 3A). No lagC transcripts were detected in RNA isolated from vegetative and 4-hr developing cells. A single $3.5-\mathrm{kb}$ band was observed in RNA isolated from wild-type cells from the loose aggregate stage $(8 \mathrm{hr})$ through culmination $(24 \mathrm{hr})$, with the level of transcript peaking at 8-10 hr. When RNA blots from AK127 cells (lagC mutant cells) were examined, no $\operatorname{lag} C$ RNA was detected, indicating that the disruption of the lagC gene results in a null phenotype.

Extracellular cAMP acting through cell-surface receptors is known to regulate the expression of many genes expressed during development (see introductory section).
The use of suspension cultures of starved cells allows one to test whether the expression of a gene might be regulated under different developmental conditions. Three protocols are used: (1) $30 \mathrm{nM}$ pulses of cAMP, which mimics cAMP signaling during the aggregation phase of development; (2) pulses followed by high continuous levels of cAMP in the absence of continuous cell-cell contact, which induces classes of prestalk-enriched genes expressed during the multicellular stages; (3) pulses followed by high continuous levels of cAMP in the presence of continuous cell-cell contact, which induces classes of prestalk-specific and prespore-specific genes expressed during the multicellular stages (see introductory section and below). Cells remain separate when shaken at high speeds in the presense of EDTA (fast-shake culture) and form stable cell-cell contacts when shaken at low speeds (slow-shake culture) (Fig. 3B; Mehdy and Firtel 1985; Datta et al. 1986). These three protocols were used to examine the effects of cAMP and cell-cell contact on $\operatorname{lag} C$ expression. Wild-type KAx-3 cells expressed $\operatorname{lag} C$ at low levels in response to nanomolar pulses of cAMP. The gene is expressed at significantly higher levels in fast-shake conditions in response to cAMP and in slow-shake cultures whether or not cAMP is present. The independence of $\operatorname{lag} C$ expression on exogenous cAMP under slow-shake conditions is often observed with genes that can be induced in fastshake culture in the presence of cAMP. This presumably is attributable to the generation of endogenous cAMP

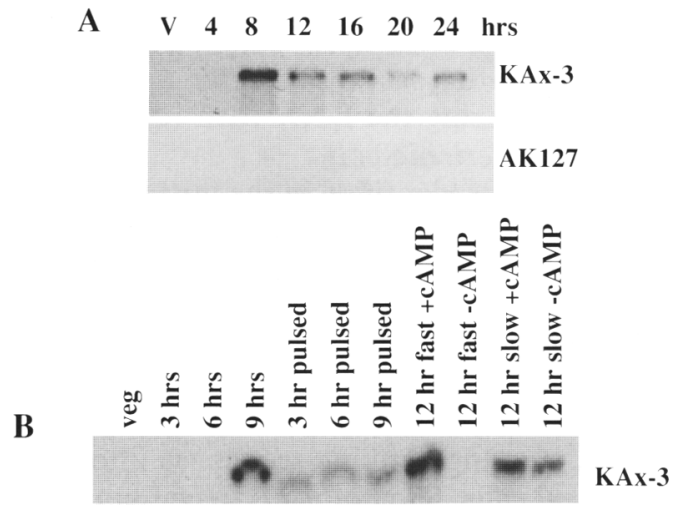

Figure 3. Developmental expression of the lagC gene in $\mathrm{KAx}-3$ and AK 127 cells plated for development or developed in shaking culture. Cells were washed, developed on filters, and harvested either as vegetatively growing cells $(\mathrm{V}$ in $A$; veg in $B)$, or at the times indicated. For cells developed in shaking culture, cells were washed and resuspended in phosphate buffer, with or without being pulsed every 6 min with 30 nM cAMP for 3,6 , or $9 \mathrm{hr}$ while shaking. Cells pulsed for $6 \mathrm{hr}$ were then split and shaken for an additional $12 \mathrm{hr}$ either fast ( $200 \mathrm{rpm}$ with $2 \mathrm{~mm}$ EDTA) or slowly $(120 \mathrm{rpm})$ in the presence or absence of $300 \mu \mathrm{M}$ cAMP. Total cellular RNA was isolated at the indicated times and conditions, size fractionated on denaturing gels, and blotted. The filters were hybridized with either a lagC genomic fragment isolated from p127Cla $(A)$ or with the lagC cDNA $(B)$. (For further experimental details and data analysis, see Materials and methods.) 
within the clumps (Mehdy and Firtel 1985). In cells shaken in the absence of cAMP, no expression is seen for the first $6 \mathrm{hr}$. Cells shaken for $9 \mathrm{hr}$ in the absence of cAMP pulses started to clump because of low endogenous cAMP oscillations (Mann and Firtel 1987) and expressed lagC mRNA. lagC transcripts were absent in AK127 cells (lagC $C^{-}$null mutant cells) when assayed in shaking culture with CAMP (data not shown). When a $\operatorname{lagC}$ probe was hybridized to mRNA isolated from Percoll gradient-separated prestalk and prespore cells (Ratner and Borth 1983; Kubahara et al. 1993), the lagC transcript was more abundant in prestalk cells than in prespore cells by a ratio of 3:1 (data not shown).

\section{Developmental morphology of lagC ${ }^{-}$null cells}

The developmental morphology of $\operatorname{lag} C^{-}$null cells was analyzed by plating washed cells on non-nutrient agar. AK127 cells aggregated to form loose mounds with kinetics similar to those of wild-type KAx-3 cells but did not form hemispherical tight aggregates (Fig. 4A). The $\operatorname{lagC} \mathrm{C}^{-}$aggregates started to dissociate at $12 \mathrm{hr}$ and often formed ring-like structures (Fig. 4B). These loose aggre- gates appeared to be in flux, with groups of cells splitting off and merging with other groups. By $17 \mathrm{hr}, \operatorname{lag} \mathrm{C}^{-}$cells had dispersed to form a rough layer only a few cells thick (Fig. 4C). The cells then synchronously formed streams and reaggregated by $24 \mathrm{hr}$ (Fig. 4D). These secondary aggregates did not fall apart again but, instead, became granular by $27 \mathrm{hr}$ (Fig. 4E), developing multiple, small, tip-like structures by $\sim 35 \mathrm{hr}$ (Fig. 4F). Depending on local conditions on the plate, most of the $\operatorname{lag} C^{-}$cells remained as aggregates at $60 \mathrm{hr}$ (Fig. 4G), but a very small fraction of $1 \mathrm{agC} \mathrm{C}^{-}$cells formed minute fruiting body-like structures (Fig. 4H). Morphogenesis was also examined in four other, independently derived $\operatorname{lag} C^{-}$derivatives of DHl generated by homologous recombination using the cloned gene. These strains showed a similar pattern of aggregation, ring formation, disaggregation, and reaggregation; however, the formation of later structures occurred to a significantly lesser degree.

The ability of $\operatorname{lag} C^{-}$null cells to form viable spores, as assayed by the presence of heat- and detergent-resistant cells, was tested (Loomis 1969; Hadwiger and Firtel 1992). When 1 lagC $C^{-}$null cells were developed, no spores $1<0.01 \%$ of cells developed on agar plates) were detected
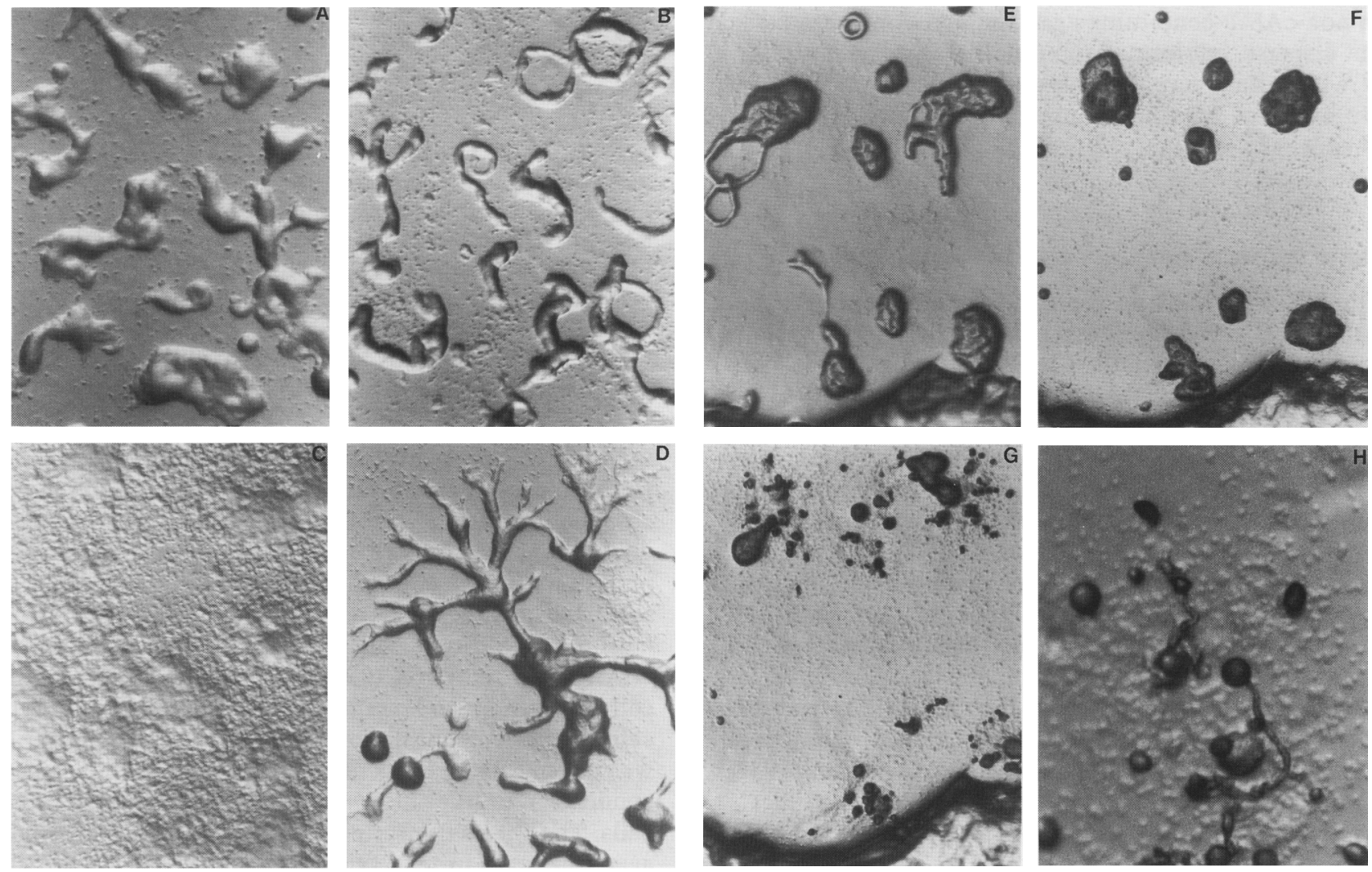

Figure 4. Developmental morphology of AK127 cells. Cells were grown axenically, washed, and plated on non-nutrient agar for development as described in Materials and methods. $(A)$ AK127 aggregates, $9 \mathrm{hr}$ after starvation; $(B)$ disaggregation of AK127 aggregates, $13 \mathrm{hr}$, showing ring-like intermediate structures; $(C)$ completely disaggregated AK127 cells, $17 \mathrm{hr} ;(D)$ AK127 cells reaggregating, $24 \mathrm{hr}$, showing large streams; $(E)$ AK127 granular aggregates, $27 \mathrm{hr} ;(F)$ AK127 aggregates with multiple tips, $40 \mathrm{hr}$; $(G)$ AK127 final morphological stage, $60 \mathrm{hr}$ (note that $E, F$, and $G$ all represent the same region of the plate taken at different times.); $(H)$ AK127 small fruiting body, $60 \mathrm{hr}$. The magnification of $H$ is approximately five times (linear dimension) greater than the other panels. 
at $36 \mathrm{hr}$, a time when spores are present in wild-type strains. Moreover, when 36 -hr structures were dissociated and examined microscopically, no spore-like cells were observed. When $\operatorname{lag} C^{-}$null cells were developed for 72-96 hr, a small number of oval, birefringent sporelike cells were seen in the few minute fruiting body-like structures. The total number of viable spores was very low $0.1-0.01 \%$ of cells developed on agar compared with $>80 \%$ for wild-type cells). These pseudo-fruiting bodies also contained some vacuolated stalk cells within the "stalk-like" region.

To examine morphogenesis further in AK127 cells and to see whether extracellular cAMP could rescue development, AK127 cells were plated on agar containing 1 mM cAMP and were compared with wild-type cells developed under the same conditions. Wild-type cells formed a ring that resulted from the outward chemotactic movement of cells as the cAMP in the agar was hydrolyzed by phosphodiesterase produced by the cells (Franke and Kessin 1992). The cells remaining in the center aggregated by $9 \mathrm{hr}$ (data not shown) and formed fruiting bodies by $21 \mathrm{hr}$ (data not shown). Development was repressed in the outer ring of cells by the high cAMP. $\operatorname{lag} C^{-}$null cells showed a similar pattern of development at $9 \mathrm{hr}$, with aggregates in the center of the plated cells (data not shown). In contrast to the situation in non-cAMP-containing agar, the lagC $\mathrm{C}^{-}$aggregates did not disperse, but formed tight, tipless aggregates at $21 \mathrm{hr}$, at which time morphogenesis ceased (data not shown). No evidence for cAMP suppression of the $\operatorname{lag}^{-}$null phenotype was observed.

\section{Developmental gene expression in $\mathrm{lagC}^{-}$null cells}

The effect of LagC on the expression of genes that are differentially regulated during development was examined by RNA blot analysis in wild-type and $\operatorname{lag} C^{-}$null cells developed on filters and in shaking culture in the presence or absence of cell-cell contact and exogenous cAMP. In $\operatorname{lag} C^{-}$null cells developed on filters, transcripts for the prestalk-enriched gene ras $D$ were barely detected, whereas transcripts for the prestalk gene ecmA and the prespore genes $S P 60(\cot A)$ and $S P 70(\cot B)$ were not detectable within $24 \mathrm{hr}$ of starvation (Fig. 5; data not shown). The prestalk-enriched gene pst-cathepsin/CP2 $(c p r B \mid$, which is induced at low levels in response to cAMP pulses during aggregation (A. Clark, G. Schnitzler, and R.A. Firtel, unpubl.) and at high levels in response to higher, continuous CAMP in the aggregate (Mehdy et al. 1983; Mehdy and Firtel 1985; Pears and Williams 1987), was expressed at significantly reduced levels in $\operatorname{lag} \mathrm{C}^{-}$ null cells compared with wild-type KAx-3 cells.

To examine the ability of exogenous cAMP to regulate prestalk and prespore gene expression, cells were starved in shaking culture (suspension), pulsed with cAMP for 6 $\mathrm{hr}$, and then shaken in the presence or absence of cAMP. In lag $C^{-}$null cells, CP2 was induced to a small extent, similar to the level seen in response to cAMP pulses in wild-type cells (Fig. 3), but further expression was not

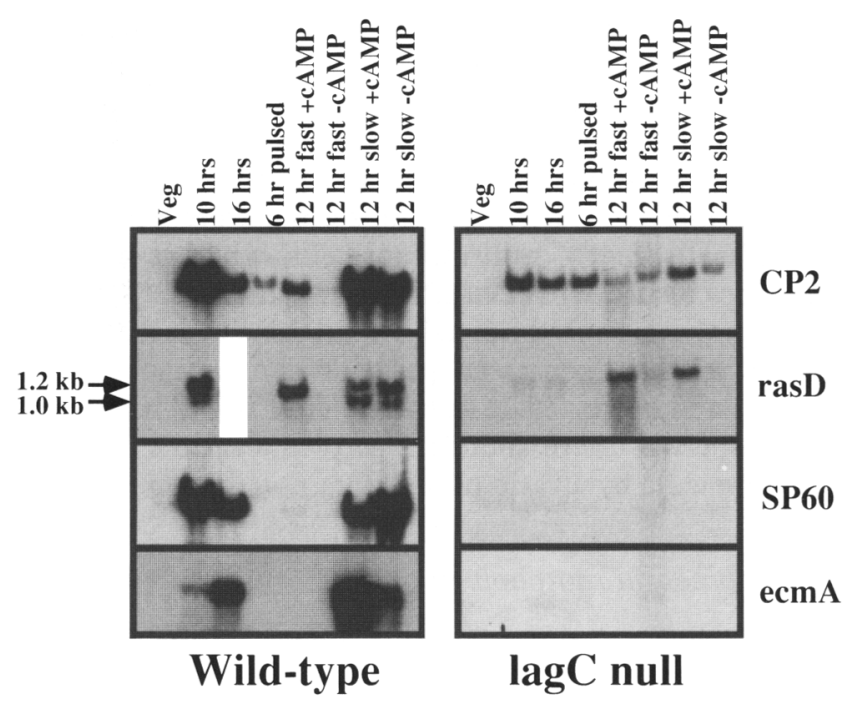

Figure 5. Developmental expression of $C P 2$ (prestalk enriched), ras $D$ (prestalk), $S P 60$ (prespore), and $e c m A$ (prestalk) in KAx-3 and AK127 cells either plated for development or developed in shaking culture. For cells developed on plates, the cells were washed and harvested as vegetatively growing cells (Veg) or plated on non-nutrient agar and harvested at 10 or $16 \mathrm{hr}$. For the cells developed in shaking culture, cells were washed and resuspended in phosphate buffer and pulsed every 6 min with 30 nM cAMP for $6 \mathrm{hr}$ while shaking. The cells were then split and shaken for an additional $12 \mathrm{hr}$ either fast $1200 \mathrm{rpm}$ with $2 \mathrm{~mm}$ EDTA) or slowly (120 rpm) in the presence or absence of $300 \mu \mathrm{M}$ cAMP. Total cellular RNA was isolated at the indicated times and conditions, size fractionated on denaturing gels, blotted, and hybridized with $C P 2$, rasD, $S P 60$, and $e c m A$ probes as described previously (Mann and Firtel 1987). The two rasD transcripts of 1.2 and $1.0 \mathrm{~kb}$ are indicated. The 16-hr wild-type KAX-3 RNA is reduced in abundance compared with the other RNAs in this series. The lane of 16-hr wild-type cell RNA probed with ras $D$ was deleted because the incorrect amount of RNA had been loaded.

induced by high, continuous cAMP. Unexpectedly, $C P 2$ mRNA accumulated under fast-shake conditions in the absence of added cAMP in $\operatorname{lag} C^{-}$null cells. rasD produces two transcripts $(1.0$ and $1.2 \mathrm{~kb})$ from independent promoters (Louvion et al. 1991; Esch et al. 1992). The ras $D 1.2$-kb transcript, which is induced in fast-shake culture in wild-type cells in response to high levels of cAMP (Esch and Firtel 1991), accumulated in lagC ${ }^{-}$null cells but to a lower level than was observed in wild-type cells (Fig. 5). Accumulation of the rasD 1.2-kb transcript was dependent on exogenous cAMP even in slow-shake conditions, unlike the pattern seen in wild-type $\mathrm{KAx}-3$ cells. The $1.0-\mathrm{kb}$ transcript, which is induced at the tight aggregate stage in wild-type cells (10-hr time point), was not observed in lagC ${ }^{-}$cells. Neither ecmA fa cAMP- and DIF-induced prestalk-specific gene) nor SP60 (presporespecific) transcripts were detected under any of these assay conditions in lagC $C^{-}$null cells (Fig. 5). The aggregation-stage, pulse-induced gene $\operatorname{csaA}(g p 80)$ was normally expressed in response to cAMP pulses in mutant cells 
(data not shown). The results indicate that genes requiring a prior period of cell-cell contact, high levels of extracellular cAMP, and possibly other extracellular signals such as $\mathrm{Ca}^{2+}$ and DIF, are not expressed to a detectable level in $\operatorname{lagC} \mathrm{C}^{-}$null cells. Genes requiring only high levels of cAMP are induced, but the mRNAs accumulate to reduced levels in the mutant cells.

Because histochemical staining for $\beta$-galactosidase activity can be more sensitive than RNA blot analysis in that it can detect expression within single cells, the activation of cell-type-specific genes was also examined using promoter-lacZ gene fusions. $\operatorname{lag} C^{-}$null cells transformed with rasD/lacZ showed very low levels of staining within the loose aggregate (data not shown). The number of stained cells and the intensity of staining decreased as the aggregates dispersed and then increased as they reformed. AK127 cells carrying an ecmA/lacZ reporter showed fewer stained cells than with the ras $D$ construct, although we observed the same general temporal pattern of $\beta$-gal staining as was seen in rasD/lac $Z$ transformed cells (data not shown). The absence of detectable ecmA transcripts by RNA blot analysis is consistent with the relatively few ecmA/lacZ cells that detectably express $\beta$-gal and the longer time period of incubation necessary to see the staining. ecmA/lacZ staining is also seen in the pseudo-fruiting bodies observed at $72-96 \mathrm{hr}$. In these aggregates, $\beta$-gal staining is observed in cells scattered through all parts of the organism, including some in the stalk-like region. The staining pattern in these cells does not show the highly defined pattern seen in wild-type cells, suggesting that these organisms the spatial patterning of the various cell types is not ordered. $\operatorname{lag} C^{-}$null cells transformed with SP60/lacZ showed no detectable expression until after the cells had reaggregated and not until development had proceeded for at least $60 \mathrm{hr}$. The expression level was very low and staining was seen only in scattered aggregates (data not shown).

\section{Mosaic analysis of lagC ${ }^{-}$null cells developed with wild-type cells}

$\operatorname{lag} \mathrm{C}^{-}$null cells carrying various $\mathrm{lacZ}$ reporter constructs were washed, mixed with wild-type KAx-3 cells in a ratio of 1:3 (mutant to wild type), and plated for development on filters. Cells were fixed and stained for $\beta$-gal expression at various times to determine whether the mutant phenotypes seen in $1 a g C^{-}$cells were altered by extracellular signals generated by wild-type cells or direct cell-cell interactions with them. To examine the general spatial pattern of $\operatorname{lag} C^{-}$null cells within the chimeras, $\operatorname{lag} C^{-}$null cells were marked by expressing the reporter construct act15/IacZ (Mann and Firtel 1993), which expresses $\beta$-gal in all cell types throughout development. Although $\operatorname{lag} C^{-}$null cells cannot proceed past the loose aggregate stage on their own in the first 24 $\mathrm{hr}$ of development, mixtures of AK127 and wild-type cells form chimeras that develop with normal morphology and timing. The $\operatorname{lag} C^{-}$null cells were randomly scattered throughout the newly formed loose aggregates
(Fig. 6A). By the slug stage, mutant cells were present throughout the organism, although there appeared to be a greater concentration of the cells toward the posterior one-third of the slug (Fig. 6B). In control mixtures of labeled and unlabeled wild-type cells, slugs were uniformly labeled (data not shown). In culminants, $\operatorname{lag} C^{-}$ null cells were found in the sorus, stalk, upper and lower cups, and basal disc (Fig. 6C,D); however, whereas lagCnull cells appeared to be randomly dispersed in the stalk, they were restricted to the lower half of the spore mass (Fig. 6C). Some lagC $C^{-}$null cells expressing $\beta$-gal had either stalk cell-like or spore-like morphology (Fig. 6D). However, when cells from 26-hr culminants were assayed for mature spores (see above), no $\operatorname{lag} C^{-}$null spores were detected $(<0.01 \%$ of wild type $)$, indicating that this aspect of development cannot be rescued by contact with wild-type cells.

When the proportion of wild-type to lag $C^{-}$null cells was reduced to $1: 1$, development became abnormal. The coaggregates formed multiple tips that developed into multiple fingers and slugs and then proceeded through development to form small, but normally proportioned, fruiting bodies. When the proportion of wild-type cells was reduced further to $3: 1$ (mutant to wild-type), multiple tips were again formed but the aggregates were more granular in structure. Although some of the cells proceeded through development (predominantly wild-type cells), most remained as loose aggregates. When the ratio was reduced further to 9:1, few tips were seen and most cells did not develop further, suggesting that the function provided by wild-type cells is limiting or nondiffusible.

To study the expression pattern of cell-type-specific genes and the spatial patterning of the individual cells types in chimeric organisms, $\operatorname{lag} C^{-}$null cells transformed with $l a c Z$ gene fusions driven by the ecmA, ras $D$, and $S P 60$, spiA, and $e c m B \Delta 89$ promoters were mixed with wild-type cells in the original $1: 3$ ratio, and the pattern of $\beta$-gal expression was examined during development (for promoter references, see Haberstroh and Firtel 1990; Ceccarelli et al. 1991; Esch and Firtel 1991; Jermyn and Williams 1991; Richardson and Loomis 1992; Mann and Firtel 1993; D. Richardson, W. Loomis, and A. Kimmel, in prep.). ecmA/lacZ is strongly expressed beginning at the loose aggregate stage and is expressed in the prestalk zone (anterior $10-15 \%$ of wildtype slugs) and in anterior-like cells (ALCs) (Jermyn and Williams 1991); however, it was expressed at extremely low levels in $\operatorname{lag} C^{-}$aggregates (see above). When $\operatorname{lag} C^{-}: e c m A / 1 a c Z$ cells were mixed with wild-type cells, we observed a temporal and spatial pattern of expression of $\beta$-gal throughout development that was very similar to that seen in wild-type:wild-type chimeras expressing ecmA/lacZ, except that the boundary between the prestalk and prespore zone was not as sharp as in wild-type slugs (Fig. 6,E-G). Moreover, the rate of staining, an indication of the level of expression, was similar in $\operatorname{lag} C^{-}: e c m A / 1 a c Z$ and wild-type:ecmA/lacZ cells when mixed with unmarked wild-type cells /data not shown), suggesting that ecmA expression and the spatial 
Figure 6. Cytological staining of act15/ lacZ, ecmA/lacZ, and SP60/lacZ constructs in AK127 cells of chimeric organisms containing a ratio of $3: 1$ untransformed KAx-3 cells to labeled AK127 cell. Cells were mixed before washing; development and staining methods are described in Materials and methods. (A) AK127 cells carrying act $15 /$ lac $Z$ mixed with $\mathrm{KAx}-3$ at the aggregate stage, $10 \mathrm{hr}$ of development; (B) act15/lacZ, slug stage, $16 \mathrm{hr}$; (C) act15/ lacZ, fruiting body stage, $24 \mathrm{hr}$; $(D) \mathrm{AK} 127$ spores and stalk cells carrying act15/lacZ, $24 \mathrm{hr}$; $(E)$ ecmA/lacZ, $10 \mathrm{hr}$; $(F)$ ecmA/ lacZ, $16 \mathrm{hr} ;(G) e c m A / l a c Z, 24 \mathrm{hr} ;(H)$ $S P 60 / 1 a c Z, 10 \mathrm{hr}$; (I) SP60/lacZ, $16 \mathrm{hr}$; (J) SP60/lacZ, $24 \mathrm{hr}$.

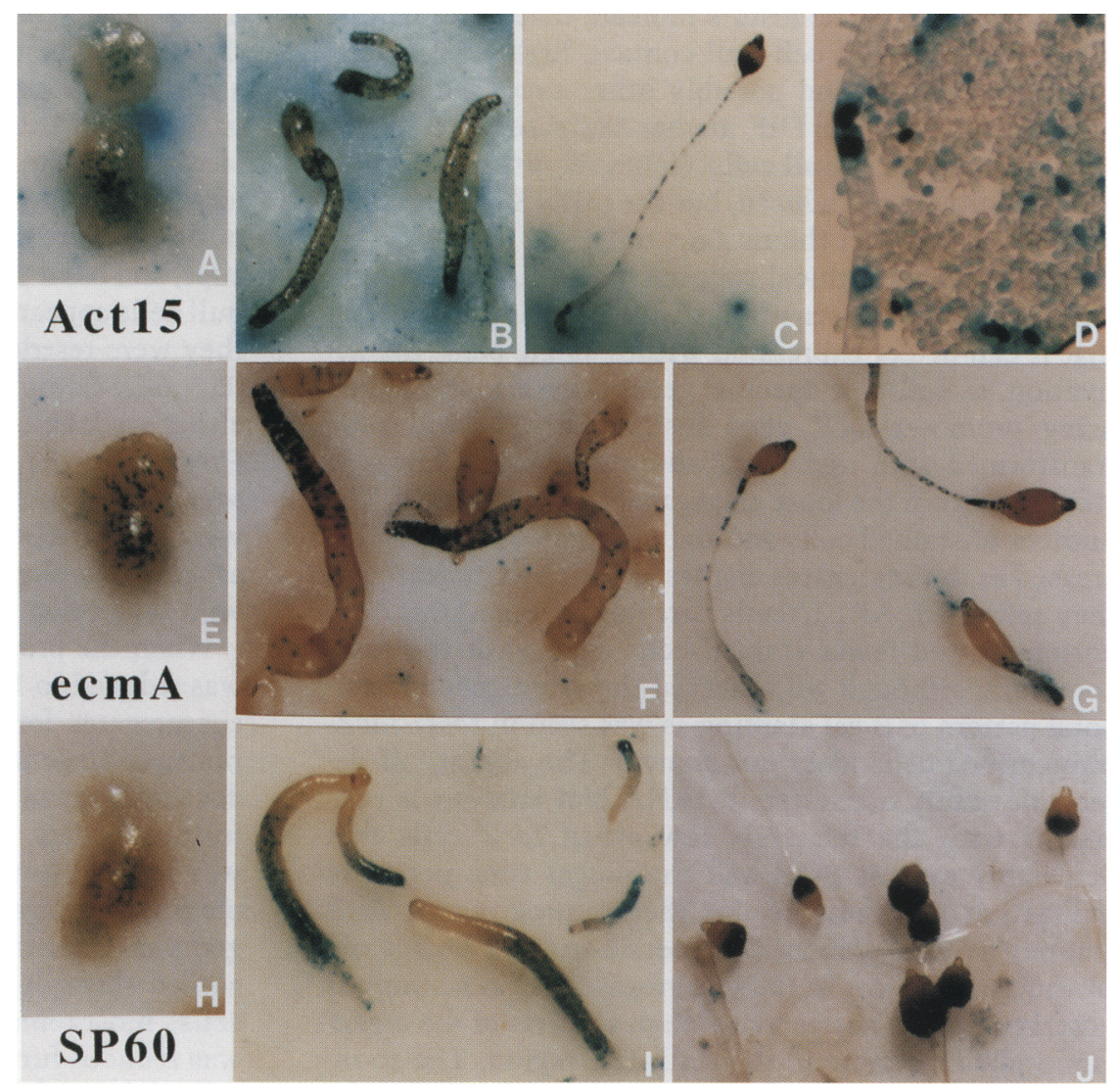

patterning of prestalk A and prestalk O cells /found in the anterior and posterior halves of the prestalk zone, respectively) were normal in $\operatorname{lag} \mathrm{C}^{-}$null cells in the chimeras. In wild-type cells, ras $D$ is detectably expressed in prestalk A and prestalk O cells, ALCs, and rear-guard cells (cells in the very posterior of the slug) (Esch and Firtel 1991). rasD/lacZ in lagC $C^{-}$null:wild-type chimeras was expressed at the expected stage of development but showed abnormal spatial regulation, with rasD/ lacZ-expressing cells being less enriched in regions occupied by prestalk A cells (anterior of the prestalk zone) (data not shown).

When SP60/lacZ-transformed lag $C^{-}$null cells were mixed with wild-type cells, $\beta$-gal-expressing cells appeared at the correct developmental stage but with an altered staining pattern (Fig. $6 \mathrm{H}-\mathrm{J}$ ). In contrast to the pattern in wild-type slugs in which the posterior $80 \%$ of the slug expresses $\beta$-gal uniformly (Haberstroh and Firtel 1990 ), stained $\operatorname{lag} C^{-}: S P 60 /$ lacZ cells were present only in the posterior $50 \%$ of the slug (Fig. 6I) and were restricted to the lower half of the spore mass (Fig. 6J). This pattern was similar to that described above with $\operatorname{lag} C^{-}$ null:act 15/1acZ cells, indicating a general exclusion of $\operatorname{lag} C^{-}$null cells from the top of the sorus (see above; Fig. 6C). spiA/lacZ, a marker for terminal spore cell differentiation, showed a similar pattern of expression as $S P 60 /$ lacZ in the sorus of chimeras (data not shown).
ecmA $A 89 /$ lacZ, a marker for stalk cell differentiation, showed that $\operatorname{lag} C^{-}$null cells participated normally in stalk cell formation (data not shown). These results indicate that wild-type cells can fully rescue prestalk and stalk cell differentiation but can only partially rescue prespore differentiation.

\section{Expression of lagC from an actin promoter} in $A K 127$ and $K A x-3$

The $\operatorname{lag} C^{-}$cDNA was cloned behind the act 15 promoter on an integrating plasmid and transformed into AK127 and $\mathrm{KAx}-3$. The resulting transformants were examined for developmental phenotypes by plating on nonnutrient agar. AK127:act15//agC, KAx-3:act15//agC, and KAx-3-untransformed control cells made tight aggregates with similar morphology and timing. Both AK127:act15/lagC and KAx-3:act15/lagC cells remained at the tight aggregate stage for 2-6 hr longer than $\mathrm{KAx}-3$ cells before continuing development and forming normal fruiting bodies complete with spores after $30 \mathrm{hr}$ (data not shown). The results indicate that act15-driven $\operatorname{lagC}$ expression in AK127 rescued the developmental arrest phenotype, consistent with the phenotype of AK127 being attributable to a loss of LagC protein. Developmental delay at the tight aggregate stage was seen in both mutant and wild-type backgrounds, indicating that 
overexpression of LagC protein was probably responsible for this delay.

\section{Discussion}

We show that the cDNA encoding the LagC protein can complement the developmental defect in AK127, indicating that the mutant phenotype results from the loss of LagC protein. The derived amino acid sequence predicts that the LagC protein has an amino-terminal signal sequence for secretion and a putative transmembrane domain that shows similarity to the membrane spanning region of several mammalian and viral cell surface proteins, including C-CAM, suggesting that it is a transmembrane protein. The large number of cysteine residues in the long amino-terminal domain of LagC suggests that this is either extracellular or lumenal and thus the short carboxy-terminal domain is presumably cytoplasmic.

The developmental morphology of $\operatorname{lag} C^{-}$null cells suggests that the initial time of action of the $\mathrm{LagC}$ protein is during the loose aggregate stage. When $\operatorname{lag} C^{-}$null cells are plated at high densities on non-nutrient agar, the cells aggregated, disaggregated, and reaggregated synchronously, as if the mutant cells failed to receive the proper signal within the loose aggregate to continue morphological development, so they then disaggregated and adopted an alternative developmental program. We expect that this disaggregation is a result of a normal, developmental down-regulation of the signaling pathways involved in aggregation combined with an inability of the aggregate to proceed further through development (Kumagai et al. 1988; Devreotes 1989; Firtel 1991). A similar phenotype is also seen with strains carrying a gene disruption of the transcription G-box binding factor (GBF) that arrests at the loose mound stage (see below; Schnitzler et al. 1994). After reaggregation, $\operatorname{lag} C^{-}$null cells form granular aggregates and some late gene expression is observed. $\operatorname{lag} C$ mRNA first starts to accumulate in wild-type cells at $8 \mathrm{hr}$ of development, just as the loose aggregate is forming. Because normal morphogenesis arrests at that stage in $\operatorname{lag} C^{-}$null cells, LagC protein appears to be required as soon as it is made. The absence of any effect of overexpressing LagC during growth and early development and a developmental delay in LagCoverexpressor cell lines at the tight aggregate stage argues for the specificity of the action of this gene at this stage.

Although there is an extremely low level of $e c m A$ expression and no expression of SP60 (through $24 \mathrm{hr}$ of development) when $\operatorname{lag} C^{-}$null cells are plated for development, these cell-type-specific genes are induced in chimeras with wild-type cells. This suggests that LagC function is, to a large extent, non-cell-autonomous. This nonautonomous function can be partially complemented only when the majority of the cells within chimeras are wild type, suggesting that LagC function is probably not catalytic or involved in regulating a diffusible molecule. We suggest that LagC acts as an essential component of a cell-cell signaling pathway, possibly a cell-surface ligand, that is necessary for later development. An alternate possibility is that LagC is an essential cell adhesion molecule. Although this latter possibility is not completely excluded, we observed no clumping of cells constitutively expressing $\operatorname{lag} C$ during the growth stage. It is possible that LagC functions as one component of a heterophilic cell-cell adhesion system. $\operatorname{lag} C^{-}$null cells that express prespore-specific genes are absent from the front of the prespore zone and the top half of the sorus in chimeras and fail to make normal spores that are resistant to heat and detergents, indicating a second, cell-autonomous role for LagC.

\section{What role does LagC play in development?}

Our results suggest that LagC protein is not required for cAMP signaling in early development. Null mutations in genes involved in pulsatile cAMP signaling such as cAR1, G $\alpha 2$, ACA, and PDE all lead to an aggregationminus phenotype (Kumagai et al. 1989; Sun and Devreotes 1991; Franke and Kessin 1992; Pitt et al. 1992). Mutations that affect cAMP-mediated processes during the aggregate stage, such as PDE overexpression or car2 null mutations, arrest development at the tight aggregate stage, after the induction of cell-type-specific gene expression (Traynor et al. 1992; Saxe et al. 1993). The LagC protein acts between these two phases of cAMP-directed development. The $\operatorname{lagC}^{-}$null phenotype also does not appear to exclusively mediate DIF signaling, as both prestalk and prespore genes are affected in $\operatorname{lag} C^{-}$null cells.

The further development of some $\operatorname{lag} C^{-}$null strains to produce very small aggregates with some abnormal small fruiting body-like structures suggests that the $\operatorname{lag} C^{-}$null phenotype is slightly leaky with regard to development past the loose aggregate stage. When AK 127 cells were grown for extended periods of time and the cells were then plated for clones, we identified strains that were capable of making abnormal-looking fruiting bodies containing heat- and detergent-resistant spores. Because these cells are still uracil prototrophs, the partial suppression is not attributable to a loss of the Pyr5-6 marker used to disrupt the $\operatorname{lag} C^{-}$gene. Presumably, the suppression is attributable to a second site mutation and suggests that LagC function can be bypassed in certain genetic backgrounds.

Studies with the $\mathrm{G}$ protein $\mathrm{G} \alpha 4$ reveal similarities to the processes affected in $\operatorname{lagC}^{-}$null cells (Hadwiger and Firtel 1992). Although $G \alpha 4$ is expressed at low levels in vegetative growth, $G \alpha 4$ transcripts accumulate to high levels at the tight aggregate stage. Overexpression of $\mathrm{G} \alpha 4$ $\left[G \alpha 4^{H c}\right.$ cells) causes loose aggregates to disperse, forming rings before reaggregating to form mutant culminants. Likewise, mutants carrying a disruption of the gene encoding the transcription factor GBF aggregate, disperse, and reaggregate and do not express CAMP-induced celltype-specific genes (Schnitzler et al. 1994). The gbf null mutation is cell autonomous; in mosaics with wild-type cells $g b f$ null cells will coaggregate but will not participate further in development. The similarity of morpho- 
logical and gene expression phenotypes suggests that GBF, G $\alpha 4$, and LagC could be linked in a common regulatory pathway.

Our data are consistent with a model in which the LagC protein either functions as a signal or is involved in establishing conditions essential for a signal critical to the transition from early to multicellular development in Dictyostelium. The synchronous disaggregation of lagC $C^{-}$mutant cells indicates that a critical signal is missing, with cells responding to its absence in a programmed way. This critical signal can be supplied, in large part, by wild-type cells in mixed populations. Moreover, the structure of the LagC protein is consistent with LagC acting as a cell-surface signal. In addition, it appears that a second cell-autonomous function of LagC is crucial for the transition of prespore cells to mature spores. Further elucidation of the function of LagC will require localizing $\mathrm{LagC}$ within the cell and the identification of interacting proteins and/or molecules that lie downstream from LagC in a possible signaling pathway.

\section{Materials and methods}

\section{Strains and media}

Cells were grown on plates or in shaking culture in HL5 medium (Sussman 1987) supplemented with vitamin B12 (Sigma) to $0.5 \mu \mathrm{M}$ and folic acid (Sigma) to $0.5 \mu \mathrm{M}$, with or without $15-30 \mu \mathrm{g} / \mathrm{ml}$ of G418 (GIBCO/BRL). Cells were also grown on plates in minimal media as described previously (Franke and Kessin 1977). Clonal isolates were obtained by plating cells in association with Klebsiella aerogenes on SM nutrient agar plates (Sussman 1987). Cells grown in HL5 or minimal medium were transformed as described previously (Dynes and Firtel 1989; Kuspa and Loomis 1992). The following constucts were transformed into Dictyostelium cells: act15/lagC (described below); act15/lacZ (Mann and Firtel 1993; G. Shaulsky and W. Loomis, unpubl.); rasD/lacZ, (Esch and Firtel 1991); SP60/lacZ (Haberstroh and Firtel 1990); ecmA/lacZ (Jermyn and Williams 1991); ecmA $489 /$ lacZ (Ceccarelli et al. 1991); spiA/lacZ (D. Richardson, W. Loomis, and A. Kimmel, in prep.); and p127Cla (Kuspa and Loomis 1992).

\section{DNA constructs and RNA blots}

The cDNA c127.1 containing the LagC-coding region, 3 '-untranslated region, and a portion of the 5 -untranslated region was isolated from a $\lambda Z A P$ (Stratagene) cDNA library made from RNA isolated from cells developed for 12-16 hr /Schnitzler et al. 1994), using a flanking probe from p127Cla (Kuspa and Loomis 1992) and standard protocols (Sambrook et al. 1989). c127.1 was cloned into the actin 15 expression vector EXP4(+) with SpeIXhoI to create act 15/lagC. EXP4|+ | was constructed as follows. The act15 promoter-2H3 terminator fragment from BS18 (Kumagai et al. 1989, 1991; Firtel and Chapman 1990) was cloned into pATSP (Dynes and Firtel 1989; Haberstroh and Firtel 1990) that had been digested with $X b a I-E c o R I$, generating EXP1. The Act6-neo selectable marker from BS18 was digested with BamHI, blunt-ended with Klenow, digested with EcoRI, and cloned into EXPl digested with EcoRI and EcoRV. A NotI linker was put into the blunt site as part of the ligation, creating EXP2. The EcoRI site in EXP2 was filled in and a NotI linker was inserted to flank Act6-neo, thus generating EXP3. A polylinker containing the following sites was inserted into the BglII site in
EXP3 to generate EXP4|+1. |Oligonucleotide restriction sites: BgIII, SpeI, EcoRI, BclI, XhoI; oligonucleotide sequence, top strand: 5' GATCTACTAGTGAATTCTGATCACTCGAG 3'.) DNA manipulation was performed using standard protocols (Sambrook et al. 1989).

RNA blots were performed as described by Mann and Firtel (1987). Analysis of gene expression in shaking cultures with cAMP was carried out as described in Mehdy and Firtel (1985). To produce the figures for publication, standard autoradiographs were scanned in an Apple Colorscanner at 300 dots per inch using Ofoto and saved as a PICT file without any manipulation of the image. The file was opened in Canvas, cropped and labeled, and saved as a PICT file. No other image manipulation was performed. The Canvas file was then printed on a Linotronic 300 printer at 1270 lines per inch.

\section{Analysis of morphology, $\beta$-galactosidase activity, spore production, and cell-type separation}

Analyses of morphology, $\beta$-galactosidase activity, and spore production were performed on cells grown axenically in shaking cultures of HL5 medium supplemented with B12/folate (see above) to mid-log phase $\left(1 \times 10^{6}\right.$ to $3 \times 10^{6}$ cells $\left./ \mathrm{ml}\right)$. To examine synchronous morphological development, cells were washed in $12 \mathrm{~mm} \mathrm{Na} / \mathrm{K}$ phosphate buffer $(\mathrm{pH} 6.1)$, resuspended at $3 \times 10^{7}$ cells $/ \mathrm{ml}$, and spread on non-nutrient agar plates.

For $\beta$-galactosidase staining, cells were spread on nitrocellulose filters that were laid on agar plates for development. Histochemical localization of $\beta$-galactosidase activity was determined using the X-gal staining procedure described in Haberstroh and Firtel (1990) and Esch and Firtel (1991).

To assay mature spore production, cells developed for $36 \mathrm{hr}$ or 5 days were washed off non-nutrient agar plates with a rubber scraper, spun down, resuspended in $10 \mathrm{~mm}$ EDTA (pH 7.2), $0.1 \%$ $\mathrm{NP}-40$, and incubated for $45 \mathrm{~min}$ at $42^{\circ} \mathrm{C}$. Cells were washed three times with phosphate buffer, resuspended in SM medium, diluted, and plated with $K$. aerogenes on SM agar plates. Plaques arose from single cells and were counted to quantitate the number of viable spore that were plated (Hadwiger and Firtel 1992).

Prestalk and prespore cell populations were purified on Percoll gradients as described by Kubahara et al. (1993).

\section{Nucleotide and amino acid sequence analysis}

Nucleotide and amino acid sequences were analyzed using the BLAST and BLOCKS programs with available data bases (GenBank, PIR, Swissprotein) (Altschul et al. 19990; Henikoff and Henikoff 1991). Hydropathy analysis was performed on a Macintosh computer using the Kyte-Doolittle method (Kyte and Doolittle 1982) with the program MacVector 3.5 (International Biotechnologies, Inc./Kodak). Amino-terminal signal sequence cleavage site was determined by the matrix-weighted method of von Heijne (1986).

\section{Acknowledgments}

We thank S. Lee for help with the assay of mature spore production, J. Powell-Coffman, G. Schnitzler, and M. Maeda for providing RNA from Percoll gradient-separated prespore and prestalk cells, R. Insall and P. Devreotes for the ura auxotroph DH-l, J. Stege for information on the lag $^{-}$insertion in AK263, R. Doolittle for help with searching the PIR amino acid sequence data base, and J. Posakony and M. McKeown for helpful discussions over the course of this work. A.K. was supported by an American Cancer Society postdoctoral fellowship. The work 
was supported by U.S. Public Health Service grants to W.F.L. and R.A.F.

The publication costs of this article were defrayed in part by payment of page charges. This article must therefore be hereby marked "advertisement" in accordance with 18 USC section 1734 solely to indicate this fact.

\section{References}

Altschul, S.F., W. Gish, W. Miller, E.W. Myers, and D.J. Lipman. 1990. Basic local alignment search tool. I. Mol. Biol. 215: 403-410.

Aurivillius, M., O.C. Hansen, M.B.S. Lazrek, E. Bock, and B. Öbrink. 1990. The cell adhesion molecule cell-CAM 105 is an ecto-ATPase and a member of the immunoglobulin superfamily. FEBS Lett. 264: 267-269.

Berks, M. and R.R. Kay. 1990. Combinatorial control of cell differentiation by CAMP and DIF-1 during development of Dictyostelium discoideum. 110: 977-984.

Ceccarelli, A., H. Mahbubani, and J.G. Williams. 1991. Positively and negatively acting signals regulating stalk cell and anterior-like cell differentiation in Dictyostelium. Cell 65: 983-989.

Chisholm, R.L., E. Barklis, and H.F. Lodish. 1984. Mechanism of sequential induction of cell-type specific mRNAs in Dictyostelium differentiation. Nature 310: 67-69.

Dangott, L.J., J.E. Jordan, R.A. Bellet, and D.L. Garbers. 1989. Cloning of the mRNA for the protein that crosslinks to the egg peptide speract. Proc. Natl. Acad. Sci. 86: 2128-2132.

Datta, S., R. Gomer, and R. Firtel. 1986. Spatial and temporal regulation of a foreign gene by a prestalk specific promoter in transformed Dictyostelium discoideum. Mol. Cell. Biol. 6: $811-820$.

Devreotes, P. 1989. Dictyostelium discoideum: A model system for cell-cell interactions in development. Science 245: 1054-1058.

Dveksler, G., M. Pensiero, C. Cardellichio, R. Williams, G. Jiang, K. Holmes, and C. Dieffenbach. 1991. Cloning of the mouse hepatitis virus (MHV) receptor: Expression in human and hamster cell lines confers susceptibility to MHV. J. Virol. 65: 6881-6891.

Dynes, J.L. and R.A. Firtel. 1989. Molecular complementation of a genetic marker in Dictyostelium using a genomic DNA library. Proc. Natl. Acad. Sci. 86: 7966-7970.

Esch, R.K. and R.A. Firtel. 1991. cAMP and cell sorting control the spatial expression of a developmentally essential celltype-specific ras gene in Dictyostelium. Genes \& Dev. 5: 921.

Esch, R.K., P.K. Howard, and R.A. Firtel. 1992. Regulation of the Dictyostelium cAMP-induced, prestalk-specific DdrasD gene: Identification of cis-acting elements. Nucleic Acids Res. 20: 1325-1332.

Firtel, R.A. 1991. Signal transduction pathways controlling multicellular development in Dictyostelium. Trends Genet. 7: 381-388.

Firtel, R.A. and A.L. Chapman. 1990. A role for cAMP-dependent protein kinase A in early Dictyostelium development. Genes \& Dev. 4: 18-28.

Fosnaugh, K.L. and W.F. Loomis. 1991. Coordinate regulation of the spore coat genes in Dictyostelium discoideum. Dev. Genet. 12: 123-132.

-1993. Enhancer regions for temporal and cell-type-specific expression of a spore coat gene in Dictyostelium. Dev. Biol. 157: 38-48.

Franke, J. and R. Kessin. 1977. A defined minimal medium for axenic strains of Dictyostelium discoideum. Proc. Natl. Acad. Sci. 74: 2157-2161.

- 1992. The cyclic nucleotide phosphodiesterases of Dictyostelium discoideum: Molecular genetics and biochemistry. Cell Signal 4: 471-478.

Gomer, R.H., S. Datta, and R.A. Firtel. 1986. Cellular and subcellular distribution of a cAMP-regulated prestalk protein and prespore protein in Dictyostelium discoideum. I. Cell. Biol. 103: 1999-2015.

Haberstroh, L. and R.A. Firtel. 1990. A spatial gradient of expression of a cAMP-regulated prespore cell-type-specific gene in Dictyostelium. Genes \& Dev. 4: 596-612.

Hadwiger, J.A. and R.A. Firtel. 1992. Analysis of Ga4, a G-protein subunit required for multicellular development in Dictyostelium. Genes \& Dev. 6: 38-49.

Henikoff, S. and J.G. Henikoff. 1991. Automated assembly of protein blocks for database searching. Nucleic Acids Res. 19: 6565-6572.

Hinoda, Y., M. Neumaier, S. Hefta, Z. Drzeniek, C. Wagener, L. Shively, L. Hefta, J. Shively, and R. Paxton. 1988. Molecular cloning of a cDNA coding for biliary glycoprotein I: Primary structure of a glycoprotein immunologically crossreactive with carcinoembryonic antigen. Proc. Natl. Acad. Sci. 85: 6959-6963.

Hooper, N.A., C. Anjard, C.D. Reymond, and J.G. Williams. 1993. Induction of terminal differentiation of Dictoystelium by cAMP-dependent protein kinase and opposing effects of intracellular and extracellular cAMP on stalk cell differentiation. Development 119: 147-154.

Jermyn, K.A. and J.G. Williams. 1991. An analysis of culmination in Dictyostelium using prestalk and stalk-specific cell autonomous markers. Development 111: 779-787.

Jermyn, K., M. Berks, R. Kay, and J. Williams. 1987. Two distinct classes of prestalk-enriched messenger RNA sequences in Dictyostelium discoideum. Development 100: 745-785.

Kimmel, A. and R. Firtel. 1983. Sequence organization in Dictyostelium: Unique structure at the $5^{\prime}$ ends of protein coding genes. Nucleic Acids Res. 11: 541-552.

- 1991. cAMP signal transduction pathways regulating development of Dictyostelium discoideum. Curr. Opin. Genet. Dev. 1: 383-390.

Konijn, T.M., D. Barkley, Y.Y. Chang, and J. Bonner. 1968. Cyclic AMP: A naturally occurring acrasin in the cellular slime molds. Am. Nat. 102: 225-233.

Krefft, M., L. Voet, J.H. Gregg, H. Mairhoffer, and K.L. Williams. 84. Evidence that positional information is used to establish the prestalk-prespore pattern in Dictyostelium discoideum aggregates. $E M B O$ J. 3: 201-206.

Kubahara, Y., M. Maeda, and K. Okamoto. 1993. Analysis of the maturation process of prestalk cells in Dictyostelium discoideum. Exp. Cell Res. 207: 107-114.

Kumagai, A., S.K.O. Mann, M. Pupillo, G. Pitt, P.N. Devreotes, and R.A. Firtel. 1988. A molecular analysis of $G$ proteins and control of early gene expression by the cell surface cAMP receptor in Dictyostelium. Cold Spring Harbor Symp. Quant. Biol. 53: 675-685.

Kumagai, A., M. Pupillo, R. Gundersen, R. Miake-Lye, P. Devreotes, and R. Firtel. 1989. Regulation and function of G $\alpha$ protein subunits in Dictyostelium. Cell 57: 265-275.

Kumagai, A., J.A. Hadwiger, M. Pupillo, and R.A. Firtel. 1991. Molecular genetic analysis of two $G \alpha$ protein subunits in Dictyostelium. J. Biol. Chem. 266: 1220-1228.

Kuspa, A. and W.F. Loomis. 1992. Tagging developmental genes in Dictyostelium by restriction enzyme-mediated integration of plasmid DNA. Proc. Natl. Acad. Sci. 89: 8803-8807.

Kyte, J. and R.S. Doolittle. 1982. A simple method for displaying 
the hydopathic character of a protein. J. Mol. Biol. 157: 105132.

Louvion, J.F., J.C. Scholder, S. Pinaud, and C.D. Reymond. 1991. Two independent promoters as well as $5^{\prime}$ untranslated regions regulate Ddras expression in Dictyostelium. Nucleic Acids Res. 19: 6133-6138.

Loomis, W. 1969. Temperature-sensitive mutants of Dictyostelium discoideum. J. Bacteriol. 99: 65-69.

- 1982. The development of Dictyostelium discoideum. Academic Press, New York.

Mann, S.K. and R.A. Firtel. 1987. Cyclic AMP regulation of early gene expression in Dictyostelium discoideum: Mediation via the cell surface cyclic AMP receptor. Mol. Cell. Biol. 7: 458-469.

. 1991. A developmentally regulated, putative serine/ threonine protein kinase is essential for development in Dictyostelium. Mech. Dev. 35: 89-101.

1993. cAMP-dependent protein kinase differentially regulates prestalk and prespore differentiation during Dictyostelium development. Development 119: 135-146.

McGeoch, D.J., A. Dolan, S. Donald, and F.J. Rixon. 1985. Sequence determination and genetic content of the short unique region in the genome of Herpes Simplex virus type 1. J. Mol. Biol. 181: 1-13.

Mehdy, M. and R. Firtel. 1985. A secreted factor and cyclic AMP jointly regulate cell-type-specific gene expression in Dictyostelium discoideum. Mol. Cell. Biol. 5: 705-713.

Mehdy, M.C., D. Ratner, and R.A. Firtel. 1983. Induction and modulation of cell type specific gene expression in Dictyostelium. Cell 32: 763-771.

Morrissey, J.H., K.M. Devine, and W.F. Loomis. 1984. The timing of cell-type-specific differentiation in Dictyostelium discoideum. Dev. Biol. 102: 414-424.

Obrink, B. 1991. C-CAM (cell-CAM 105) - A member of the growing immunoglobulin superfamily of cell adhesion proteins. BioEssays 13: 227-234.

Pears, C. and J. Williams. 1987. Identification of a DNA-sequence element required for efficient expression of a developmentally regulated and cAMP-inducible gene of Dictyostelium discoideum. EMBO J. 6: 195-200.

Pears, C., H. Mahbubani, and J. Williams. 1985. Characterization of two highly diverged but developmentally co-regulated cysteine proteinase genes in Dictyostelium discoideum. Nucleic Acids Res. 13: 8853-8861.

Pitt, G.S., N. Milona, J. Borleis, K.C. Lin, R.R. Reed, and P.N. Devreotes. 1992. Structurally distinct and stage-specific adenylyl cyclase genes play different roles in Dictyostelium development. Cell 69: 305-315.

Powell-Coffman, J.A. and R.A. Firtel. 1994. Characterization of a novel Dictyostelium discoideum prespore-specifc gene, $P s p B$, reveals conserved regulatory elements. Development (in press).

Raper, K. 1940. Pseudoplasmodium formation and organisation in Dictyostelium discoideum. I. Elisha Mitchell Sci. Soc. 59: $241-282$.

Ratner, D. and W. Borth. 1983. Comparison of differentiating Dictyostelium discoideum cell-types separated by an improved method of density gradient centrifugation. Exp. Cell Res. 143: 1-7.

Reymond, C., R. Gomer, M. Mehdy, and R. Firtel. 1984. Developmental regulation of a Dictyostelium gene encoding a protein homologous to mammalian ras protein. Cell 39: 141148.

Richardson, D.L. and W.F. Loomis. 1992. Disruption of the sporulation-specific gene spiA in Dictyostelium discoideum leads to spore instability. Genes \& Dev. 6: 1058-1070.
Sambrook, J., E.F. Fritsch, and T. Maniatis. 1989. Molecular cloning: A laboratory manual, 2nd ed. Cold Spring Harbor Laboratory Press, Cold Spring Harbor, New York.

Saxe C.L. III, G.T. Ginsburg, J.H. Louis, R. Johnson, P.N. Devreotes, and A.R. Kimmel. 1993. CAR2, a prestalk cAMP receptor required for normal tip formation and late development of Dictyostelium discoideum. Genes \& Dev. 7: 262272.

Schaap, P. 1991. Intercellular interactions during Dictyostelium development. In Microbial cell-cell interactions (ed. M. Dworkin), pp. 147-176. American Society for Microbiology, Washington, D.C.

Schnitzler, G.R., W.H. Fischer, and R.A. Firtel. 1994. Cloning of the G-box binding factor, an essential component of the developmental switch between early and late development in Dictyostelium. Genes \& Dev. 8: 502-514.

Sun, T.J. and P.N. Devreotes. 1991. Gene targeting of the aggregation stage cAMP receptor cAR1 in Dictyostelium. Genes \& Dev. 5: 572-582.

Sussman, M. 1987. Cultivation and synchronous morphogenesis of Dictyostelium under controlled experimental conditions. Methods Cell Biol. 28: 9-15.

Traynor, D., R.H. Kessin, and J.G. Williams. 1992. Chemotactic sorting to cAMP in the multicellular stages of Dictyostelium development. Proc. Nat1. Acad. Sci. 89: 8303-8307.

von Heijne, G. 1986. A new method for predicting signal sequence cleavage sites. Nucleic Acids Res. 14: 4683-4690.

Williams, J.G. 1991. Regulation of cellular differentiation during Dictyostelium morphogenesis. Curr. Opin. Genet. Devel. 1: 358-362.

Williams, J.G., A. Ceccarelli, S. McRobbie, H. Mahbubani, R.R. Kay, A. Early, M. Berks, and K.A. Jermyn. 1987. Direct induction of Dictyostelium prestalk gene expression by DIF provides evidence that DIF is a morphogen. Cell 49: 185192.

Williams, J.G., K.T. Duffy, D.P. Lane, S.J. McRobbie, A.J. Harwood, D. Traynor, R.R. Kay, and K.A. Jermyn. 1989. Origins of the prestalk-prespore pattern in Dictyostelium development. Cell 59: 1157-1163. 


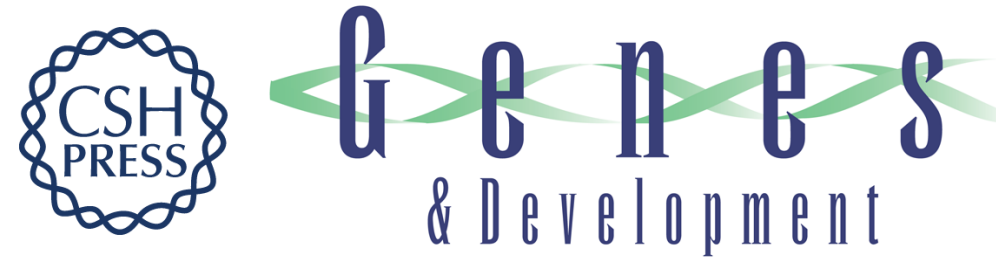

\section{LagC is required for cell-cell interactions that are essential for cell-type differentiation in Dictyostelium.}

J L Dynes, A M Clark, G Shaulsky, et al.

Genes Dev. 1994, 8:

Access the most recent version at doi:10.1101/gad.8.8.948

References This article cites 61 articles, 26 of which can be accessed free at:

http://genesdev.cshlp.org/content/8/8/948.full.html\#ref-list-1

License

Email Alerting

Service

Receive free email alerts when new articles cite this article - sign up in the box at the top right corner of the article or click here.

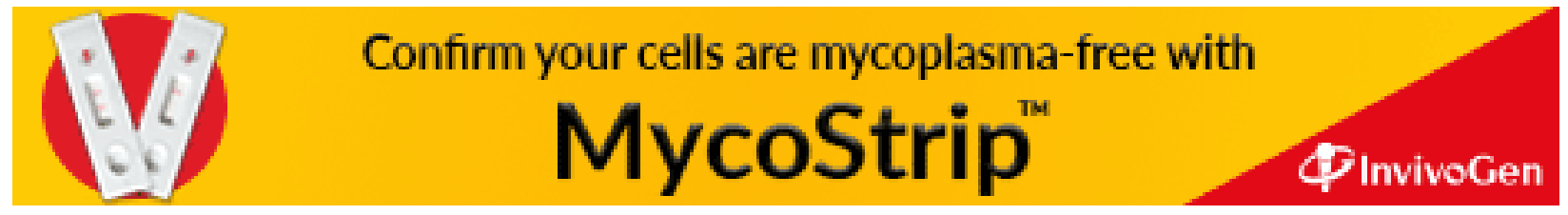

